\title{
ALTERAÇÕES ELETRENCEFALOGRÁFICAS RELACIONADAS A DEFICIENCIAS NUTRITIVAS
}

\author{
VALERIANA MoURA RIBEIRo*. \\ Rubens Moura Ribeiro **
}

\author{
T. BRAGA MONTELli * \\ EDGARD ROLANDO***
}

A influência das carências alimentares parciais ou globais sôbre a estrutura e a função do sistema nervoso é bastante connhecida ${ }^{5}, 7$.

$\mathrm{O}$ caráter reversível dos sinais neurológicos evidenciados em crianças com deficiências nutritivas sugere que novas investigaçōes sejam conduzidas com o intuito de se conhecer melhor algumas das alterações funcionais do sistema nervoso ${ }^{11}$.

Nessas condições, torna-se importante estabelecer critérios para avaliação do comprometimento encefálico de crianças desnutridas, através da avaliação conjunta de dados clínicos e laboratoriais. Como recurso subsidiário para estudo do sistema nervoso em pacientes desnutridos, o eletrencefalograma (EEG) representa uma técnica capaz de fornecer as caracteristicas bioelétricas do sistema nervoso central nas crianças sob carência alimen$\operatorname{tar} 5,6,9,10$. As características bioelétricas da maturação cerebral determinadas pelo EEG, obedecem a certos padrões que permitem estabelecer se o quociente de desenvolvimento neuromotor acompanha, ou não, a idade cronológica. A finalidade do presente trabalho é demonstrar o efeito das deficiências nutritivas sôbre o sistema nervoso, utilizando critérios de avaliação clínica e eletrencefalográfica.

\section{MATERIAL, MÉTODO E RESULTADOS}

O material consta de 20 pacientes desnutridos, sendo 10 do sexo femínino e 10 do masculino, cujas idades variavam entre três e 72 meses. Os pacientes foram admitidos no Departamento de Pediatria da Faculdade de Medicina de Ribeirão Prêto com o diagnóstico de desnutrição global ou protêica, segundo critério clínico e laboratorial. Para avaliação do grau e tipo de desnutrição foram considerados o sexo, idade, pêso e estatura dos pacientes e realizados exames para determinação, no sangue, das taxas das proteinas globais e frações, colesterol, glicose, fósforo, fosfatase alcalina, cálcio, sódio, potássio, cloro e da osmolaridade.

O EEG foi realizado em aparelho Grass de 8 canais com eletrodos colocados segundo a técnica internacional. Nos 20 pacientes os exames foram realizados durante o sono induzido pelo Seconal, administrado por via oral na dosagem de $7 \mathrm{mg} / \mathrm{kg} \mathrm{de}$ pêso corporal.

Departamentos de Neurologia (Prof. J. Armbrust Figueiredo) e de Pediatria (Prof. J. R. Woiski) da Faculdade de Medicina de Ribeirão Prêto: * Assistente de Neurologia; ** Docente de Neurologia; *** Assistente de Pediatria. 
Os traçados foram analisados com o intuito de se evidenciar a presença de elementos patológicos (onda-ponta, onda aguda) ou não (onda lenta contínua) ou da atividade fisiológica paroxística (onda do vertex, complexo $\mathrm{K}$ e fusos do sigma).

Os resultados eletrencefalográfıcos foram comparados com um grupo contrôle constituído por 20 crianças normais do ponto de vista nutricional e neurológico.

No quadro 1 estão assinalados os dados de identificação dos pacientes e os respectivos comemorativos físicos; no quadro 2 os resultados dos diferentes exames bioquímicos e, no quadro 3 , os achados eletrencefalográficos obtidos da correlação entre os pacientes com desnutrição global ou protêica e o grupo contrôle.

\begin{tabular}{|c|c|c|c|c|c|c|}
\hline & Caso & Sexo & Cor & $\begin{array}{l}\text { Tdade } \\
\text { (meses) }\end{array}$ & $\begin{array}{l}\text { Peso } \\
\text { (g) }\end{array}$ & $\begin{array}{c}\text { Estatura } \\
(\mathrm{cm})\end{array}$ \\
\hline \multirow{11}{*}{ 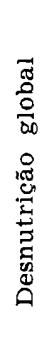 } & 1 & $\mathrm{f}$ & p & 7 & 3910 & 60 \\
\hline & 2 & $\mathrm{~m}$ & $p$ & 15 & 4970 & 64 \\
\hline & 3 & f & p & 14 & 6150 & 67 \\
\hline & 4 & $\mathrm{f}$ & b & 4 & 2630 & 56 \\
\hline & 5 & f & b & 8 & 3910 & 59 \\
\hline & 6 & $\mathrm{f}$ & $p$ & 21 & 7300 & 73 \\
\hline & 7 & $\mathrm{~m}$ & b & 4 & 3700 & 57 \\
\hline & 8 & $\mathrm{~m}$ & b & 3 & 3300 & 53 \\
\hline & 9 & $\mathrm{~m}$ & b & 24 & 8300 & 81 \\
\hline & 10 & $\mathrm{f}$ & $\mathrm{p}$ & 28 & 5950 & 64 \\
\hline & 11 & $\mathbf{f}$ & $\mathrm{p}$ & 72 & 9100 & 88 \\
\hline \multirow{9}{*}{ 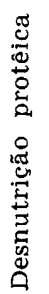 } & 1 & $\mathrm{f}$ & b & 14 & 8120 & 68 \\
\hline & 2 & f & $p$ & 17 & 6450 & 72 \\
\hline & 3 & $\mathrm{~m}$ & b & 28 & 8630 & 64 \\
\hline & 4 & f & b & 27 & 9520 & 77 \\
\hline & 5 & $\mathrm{~m}$ & b & 16 & 7750 & 71 \\
\hline & 6 & $\mathrm{~m}$ & b & 24 & 6730 & 71 \\
\hline & 7 & $\mathrm{~m}$ & b & 33 & 1650 & 74 \\
\hline & 8 & $\mathrm{~m}$ & b & 20 & 7950 & 75 \\
\hline & 9 & $\mathrm{~m}$ & b & 28 & 8200 & 79 \\
\hline
\end{tabular}

Quadro 1 - Identificą̧̃a e distribuicão dos pacientes com desnutrição global e protêica

\section{COMENTARIOS}

Embora nossos resultados tenham confirmado, de modo geral, trabalhos anteriores, êsses achados aliados às informações fornecidas pela literatura tornam evidente que o EEG de crianças desnutridas tem valor informativo para o diagnóstico de lesão orgânica do encéfalo e permite, também, avaliar os aspectos evolutivos e determinar as possiveis seqüelas.

Do ponto de vista eletrencefalográfico, nossos resultados globais acusam alterações na organização dos elementos paroxísticos fisiológicos do sono em $27,2 \%$ dos pacientes com desnutrição global e em $44,4 \%$ dos pacientes com desnutrição protêica. Atividade paroxística patológica focal foi registrada em $9 \%$ dos pacientes com desnutrição global e em $66 \%$ dos pacientes com 


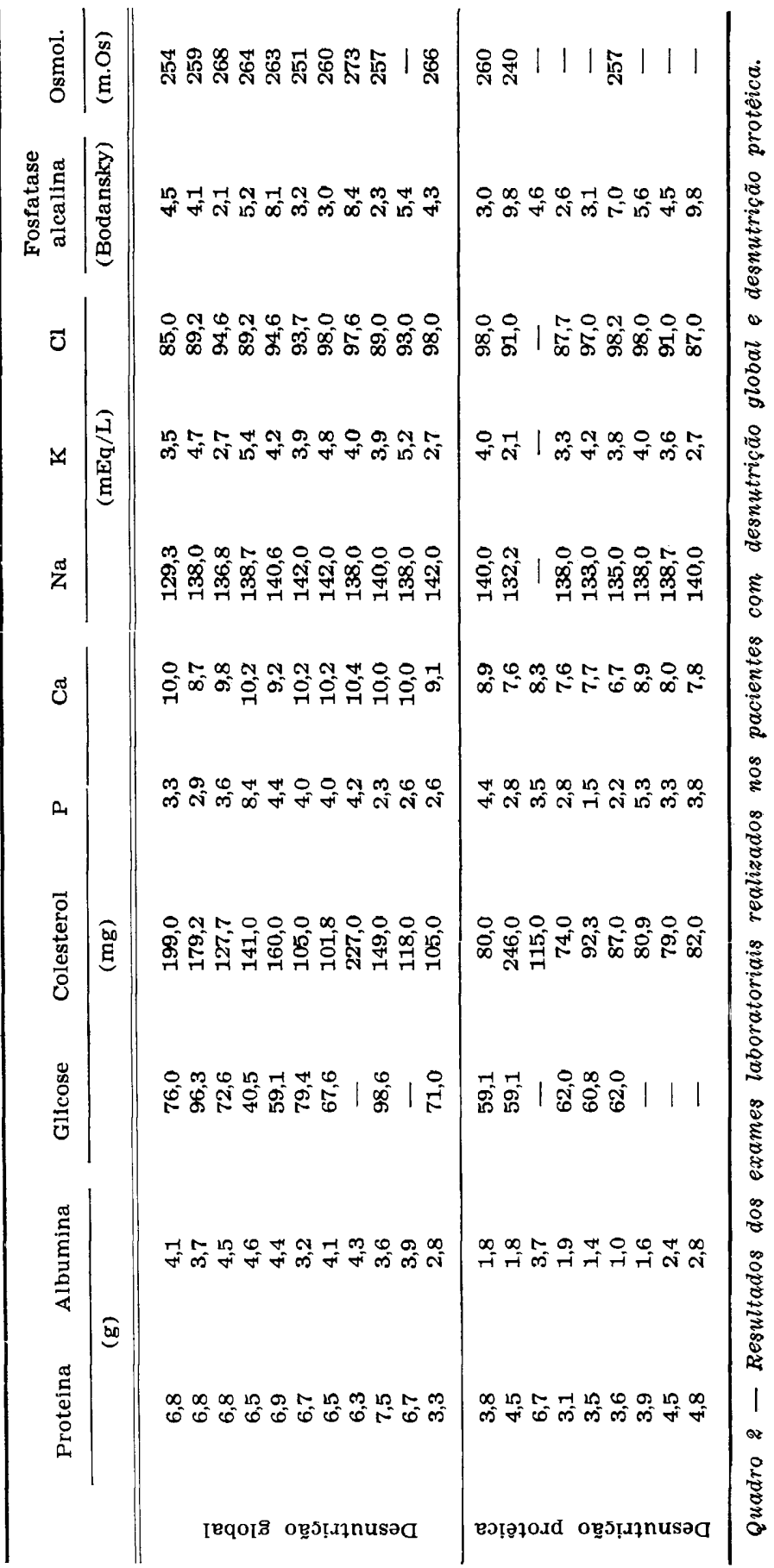


desnutrição protêica. Esses resultados, quando comparados com o grupo contrôle, evidenciam a predominância dos elementos patológicos nos pacientes com desnutrição protêica (Quadro 3).

Atividade paroxística

fisiológica

N \%
Atividade paroxística patológica

N \%

$\begin{array}{lrlll}\text { Grupo contrôle } & 3 & 27,2 & 1 & 9 \\ \text { Desnutrição protêica } & 4 & 44,4 & 6 & 66,6 \\ \text { Grupo controle } & 20 & 100 & 6 & 30\end{array}$

Quadro 3 - Resultados globais do EEG nos pacientes desnutridos e no grupo controle.

Os distúrbios do metabolismo intermediário das proteínas provocam alterações eletrencefalográficas difusas, associadas, ou não, a onda-ponta e a onda lenta trifásica. Entretanto, essas anormalidades são lábeis e estão na dependência direta dos níveis sangüineos das substâncias nitrogenadas não protêicas ${ }^{8}$. Por outro lado, a incidência relativamente elevada de alterações focais em nossos pacientes com desnutrição protêica pode ser decorrente do baixo limiar convulsiógeno provocado pela super-hidratação intracelular comumente evidenciada na má nutrição grave e crônica, conseqüente ao baixo teor de proteína calórica ${ }^{3}$.

Do ponto de vista experimental êsse baixo teor de proteína não representa o único fator causal dos sintomas neurológicos. Chan-Nao e Windle ${ }^{2}$ estudaram as alterações do corpo celular e da substância de Nissl do cérebro de cobaias que morreram de inanição e verificaram que as alterações encontradas nas células nervosas eram secundárias ao acúmulo do produto do catabolismo e da anoxia histotóxica.

Mais recentemente Cuparencu e col. ${ }^{4}$ demonstraram que cérebros de ratos brancos nutridos com regime pobre em proteínas, evidenciavam alterações do metabolismo de cerebrosídios, proteolipídios, fosfolipídios e colesterol.

As alterações eletrencefalográficas manifestadas em nossos pacientes demonstram comprometimento cerebral difuso, associado a sinais focais de tipo epiléptico.

Convém lembrar que êsses resultados não são òbviamente específicos de determinado distúrbio metabólico, mas são registrados também em várias outras condições clínicas.

\section{R E S U M O}

Foram estudadas as alterações eletrencefalográficas em 20 crianças desnutridas. Foi assinalada diferença significativa entre o EEG dos pacientes com desnutrição global e daqueles com desnutrição protêica. Essas alterações foram caracterizadas pela presença de anormalidades encefálicas di- 
fusas e/ou descargas focais de tipo epiléptico. A incidência relativamente alta de descargas focais pode ser explicada pelo limiar convulsiógeno muito baixo do cérebro de crianças com desnutrição.

\section{S U M M A R Y}

\section{Electroencephalographic changes related to nutritional deficiencies}

The EEG changes in a group of 20 children with nutritional disorders are reported. The results suggest a significant difference in the EEG of patients with undernutrition and those with protein-caloric deficiency. These alterations correspond to the incidence of diffuse cerebral involvement and or discharges of an epileptic focal activity. The relatively high incidence of focal discharges may be explained on the hasis of a very low epileptiform threshold of the cerebral cortex in children with nutritional disease.

\section{R E F E R E N CIA S}

1. CADILHAC, J. \& RIBSTEIN, M. - The EEG in metabolic disorders. World Neurol. 2:296, 1961 .

2. CHAN-NAO, L. \& WINDLE, 'W. F. - Effects of inanition on the central nervous system: an experimental study on the guinea pig. Arch. Neurol. \& Psychiat. 63:918, 1950 .

3. CRAVIOTO, J.; De LICARDIE, E. R. \& BIRCH, H. G. - Nutrition, growth and neuro-integrative development: an experimental and ecologic study. Pediatrics 38:319, 1966.

4. CAPARENCU, B.; ROSEMEBRG, A. \& DAPHIE, V. - L'influence de la carence preotéique sur le cerveau. World Neurol. 3:431, 1962.

5. ENGEL, R. - Abnormal brain wave patterns in kwashiorkor. Electroenceph. clin. Neurophysiol. 8: 489, 1956.

6. NELSON, G. K. \& DEAN, R. F. A. - The electroencephalogram in African children: effects of kwashiorkor and a note on the newborn. Bull. WHO 21: $779,1959$.

7. PLATT, B. S. \& WHEELER, E. F. - Protein-caloric deficiency and the central nervous system. Develop. Med. Child. Neurol. 9:104, 1967.

8. POSER, C. M. EEG changes and hyperammonemia. Electroenceph. clin. Neurophysiol. 10:51, 1958 .

9. SARRONY, Ch.; SAINT-JEAN, M. \& CLAUSSE, J. - L'électroencéphalogramme au cours de la dystrophie nutritionelle oedémateuse. Algér. méd. 57:584, 1953.

10. VALENZUELA, R. H.; HERNANDEZ-PENICHE, J. \& MACfAS, R. - Aspectos clínicos y psícológicos en la recuperación del niño desnutrido. Gaceta méd. México 89:651, 1959.

11. VICTOR, M. \& DREYFUS, P. M. - Nutritional diseases of the nervous system: a statement of some current problems and suggestions for further investigation. World Neurology 2:862, 1961 .

Departamento de Neurologia - Faculdade de Medicina - Ribeirão Prêto, SP Brasil. 